\title{
Anna Ascenzi, Drammi privati e pubbliche virtù. La maestra italiana dell'Ottocento tra narrazione letteraria e cronaca giornalistica
}

Macerata, Edizioni Università di Macerata, 2012, 394 p.

\section{Michel Ostenc}

\section{(2) OpenEdition Journals}

\section{Édition électronique}

URL : http://journals.openedition.org/assr/25860

DOI : $10.4000 /$ assr. 25860

ISSN : $1777-5825$

\section{Éditeur}

Éditions de l'EHESS

Édition imprimée

Date de publication : 31 décembre 2014

Pagination : 113

ISBN : 978-2-7132-2467-6

ISSN : 0335-5985

\section{Référence électronique}

Michel Ostenc, « Anna Ascenzi, Drammi privati e pubbliche virtù. La maestra italiana dell'Ottocento tra narrazione letteraria e cronaca giornalistica », Archives de sciences sociales des religions [En ligne], 168। 2014, mis en ligne le 30 mars 2015, consulté le 22 septembre 2020. URL : http://

journals.openedition.org/assr/25860; DOI : https://doi.org/10.4000/assr.25860 


\section{Anna Ascenzi, Drammi privati e pubbliche virtù. La maestra italiana dell'Ottocento tra narrazione letteraria e cronaca giornalistica}

Macerata, Edizioni Università di Macerata, 2012, 394 p.

Michel Ostenc

\section{RÉFÉRENCE}

Anna Ascenzi, Drammi privati e pubbliche virtù. La maestra italiana dell'Ottocento tra narrazione letteraria e cronaca giornalistica, Macerata, Edizioni Università di Macerata, 2012,394 p. 
1 L'auteur entend utiliser les réactions de la presse italienne des années 1880 au suicide d'une maîtresse d'école pour élargir le débat à une étude de la condition des institutrices dans la péninsule à la fin $\mathrm{du} \mathrm{XIX}^{\mathrm{e}}$ siècle. Le drame était double puisqu'il concernait non seulement le peu de considération dont jouissait la profession d'enseignant à l'époque, mais aussi la discrimination à l'égard de la femme, celle des classes humbles en particulier. Anna Ascenzi s'appuie sur des textes parus entre 1880 et 1900 pour montrer l'évolution de la condition des institutrices pendant cette période. Ces documents sont reproduits en annexes dans la seconde partie de l'ouvrage.

2 Les écrits de l'écrivaine napolitaine

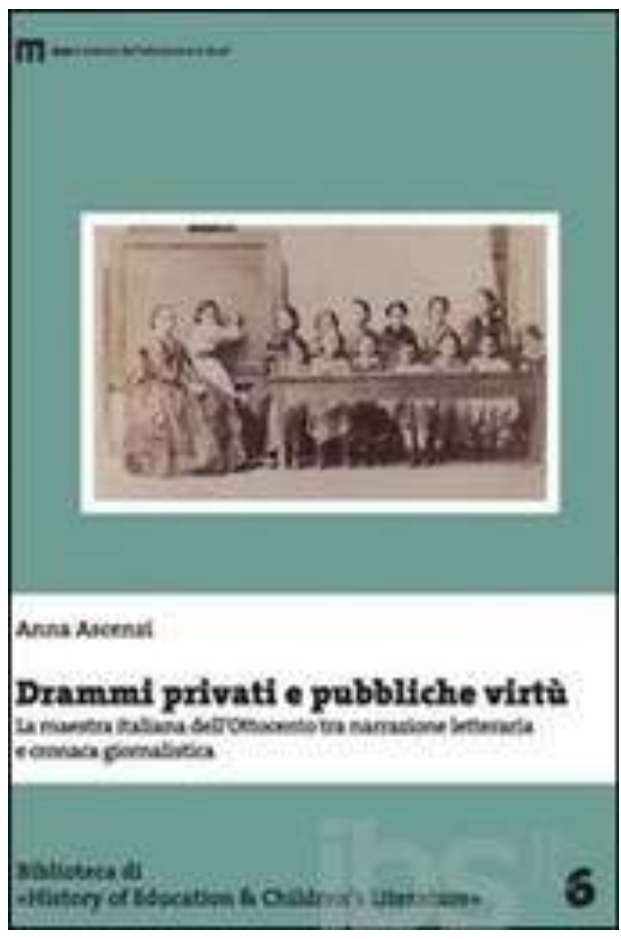
Matilde Serao soulignent les faiblesses de la formation des institutrices. Elles entraient à l'École normale sans disposer des connaissances de base indispensables, les centres ruraux ne disposant pas d'établissements susceptibles de compléter leurs études après l'enseignement primaire. L'École normale dispensait une culture générale, mais leur pédagogie se limitait à des valeurs morales et patriotiques étrangères à toute formation didactique. Un enseignement de catéchisme et d'histoire sainte s'avérait incapable de déboucher sur une réflexion collective à propos des thèmes abordés. Il contribuait à entretenir une image religieuse de la formation magistrale, la vocation enseignante restant considérée comme un don de Dieu en dépit des mesures de laïcisation de l'Instruction publique. Les Écoles normales s'avéraient inadaptées à la lutte contre l'analphabétisme qui aurait dû être leur priorité. Elles s'obstinaient à dispenser un enseignement de travaux féminins dénué de tout aspect technique qui reposait sur les lieux communs d'une distinction stricte entre les classes supérieures et celles des basses gens. Les inspectrices des écoles primaires chargées de vérifier le respect des programmes accomplissaient leur travail gratuitement comme un devoir de charité envers des filles pauvres. L'école populaire italienne semblait incapable de prendre en compte l'étendue de sa fonction sociale. La conception de la condition magistrale féminine de Matilde Serao s'éloignait par contre de toute vocation abstraite ; elle reposait au contraire sur un engagement conscient de sa fragilité et de ses limites. La seule vocation authentique se réalisait à travers la difficile approche d'une vérité s'émancipant des stéréotypes et des préjugés. Dans "Il romanzo di un maestro " d'Edmondo De Amicis, la maîtresse d'école échappait à son destin en repoussant sa féminité pour se transformer en virago; mais l'image plus complexe de l'institutrice était celle d'une icône de l'abnégation et de l'esprit de sacrifice, une sorte de martyr laïque de l'instruction populaire et de l'émancipation féminine. Elle connaissait une fin heureuse, typique de la féérie des romans de De Amicis, qui n'enlevait rien à l'inexorable tristesse de son destin. 
3 Les luttes pour l'émancipation des femmes ne présentaient aucun caractère révolutionnaire dans «Il romanzo di una maestra» d'Annetta Fusinetti (1891); mais la dimension chrétienne de la vie et l'image biblique de la justice immanente ne semblaient plus fournir les réponses à celles qui ne se résignaient pas à accepter leur dépendance. Le problème fondamental était de créer les conditions permettant à la nouvelle génération issue de la société industrielle moderne de s'adapter aux comportements et aux modes de pensée dominants. Dix ans plus tard «Il romanzo d'una maestra » d'Ida Baccini évoquait un univers très différent. L'auteur avait dû abandonner l'enseignement, son fils unique étant né de père inconnu, et elle vivait de ses écrits de littérature pour l'enfance. Ses œuvres typiquement post-risorgimentales restaient respectueuses des schémas sociaux et des traditions religieuses; mais les institutrices du début $\mathrm{du} \mathrm{xx}^{\mathrm{e}}$ siècle n'étaient plus les mêmes. Elles étaient issues de la petite bourgeoisie et avaient connu plus souvent la formation des Écoles normales. Elles enseignaient dans leur localité d'origine et n'étaient plus victimes du déracinement qui mettait leurs aînées à la merci des édiles de villages de campagne. Elles menaient une existence plus aisée où la profession d'enseignante leur permettait de construire leur identité personnelle et d'assumer un rôle social. À l'époque où se formait la première organisation nationale d'enseignants (Unione Magistrale Nazionale), les institutrices italiennes connaissaient leurs droits et étaient prêtes à les faire respecter. L'ouvrage d'Anna Ascenzi annonce l'éclosion du féminisme en Italie ; celui-ci remonte sans doute à la publication autobiographique de "Una donna » (1906) qui valut une réputation internationale à son auteur, Sibilla Aleramo. 